\title{
Unraveling the role of genetics in the pathogenesis of diabetic retinopathy
}

\author{
Ashok Sharma $^{1,2} \cdot$ Maria L. Valle ${ }^{1} \cdot$ Connor Beveridge ${ }^{1} \cdot$ Yutao Liu $^{1,3} \cdot$ Shruti Sharma ${ }^{1,4}$
}

Received: 24 May 2018 / Accepted: 31 October 2018 / Published online: 24 January 2019

(c) The Royal College of Ophthalmologists 2019

\begin{abstract}
Diabetic retinopathy (DR) is a microvascular disease of the retina and the leading cause of visual disability in diabetic patients. Genetic factors have shown to play a pivotal role in DR onset, and several candidate genes have been associated with its progression. A literature search was performed to identify the genes known to be associated with DR through linkage analysis, candidate gene association, and genome-wide association studies (GWAS). A further literature search was performed to discover their potential connection with various biological pathways. A total of 65 genes were found and several of these genes belong to major signaling pathways known to play a significant role in DR, including systemic inflammation, angiogenesis, and neurogenesis. A comprehensive analysis presented in this review will be helpful in unraveling the role of genetics in the pathogenesis of DR.
\end{abstract}

\section{Background}

Diabetic retinopathy (DR) is one of the major microvascular complications of diabetes [1]. According to its severity, DR can be classified into non-proliferative diabetic retinopathy (NPDR) and proliferative diabetic retinopathy (PDR). Hallmarks of NPDR include microaneurysms, hard exudates, cotton wool spots, intra-retinal micro-vascular abnormalities, and venous beading [2]. This condition can either remain stable or progressively develop into PDR which is characterized by neovascularization, pre-retinal hemorrhage, and vitreous hemorrhage [3]. The precise mechanisms underlying DR etiology have not been fully elucidated, and consequently, the currently available therapies are insufficient to reverse or

Shruti Sharma

shsharma@augusta.edu

1 Center for Biotechnology and Genomic Medicine, Medical College of Georgia, Augusta University, Augusta, GA 30912, Georgia

2 Department of Population Health Sciences, Medical College of Georgia, Augusta University, Augusta, GA 30912, Georgia

3 Department of Cellular Biology and Anatomy, Medical College of Georgia, Augusta University, Augusta, GA 30912, Georgia

4 Department of Ophthalmology, Medical College of Georgia, Augusta University, Augusta, GA 30912, Georgia prevent diabetic complications of the eye [1, 4-6]. Several genetic studies including linkage analysis, candidate gene association, and genome-wide association studies (GWAS) have identified a total of 65 genes associated with DR (Fig. 1). Most of the genes associated with DR have been identified through candidate gene-based association studies and GWAS (Table 1) [7-19].

To improve our understanding of the functional role of these genetic factors in DR pathogenesis, we mapped

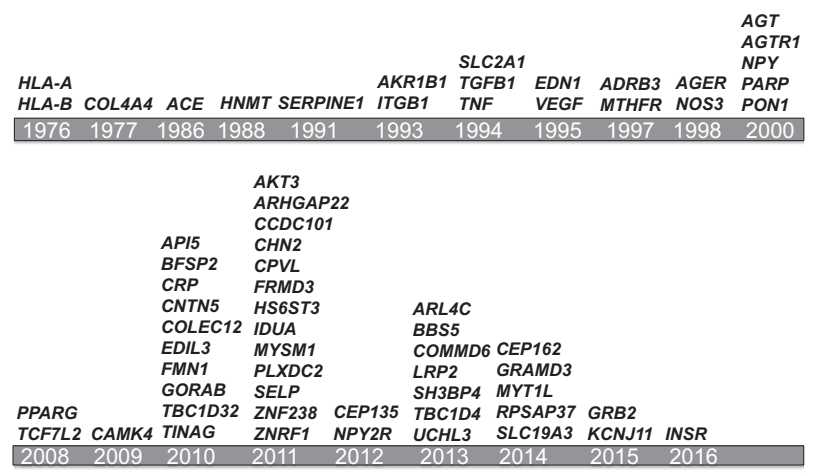

Fig. 1 Chronological list of genes associated with diabetic retinopathy. A comprehensive search of published literature was performed to generate a list of all the genes associated with diabetic retinopathy. Before 2007, most of the genes were discovered using linkage analysis or candidate gene approach. After 2007, the evolution of genome wide association studies (GWAS) led to the discovery of a large number of genes 


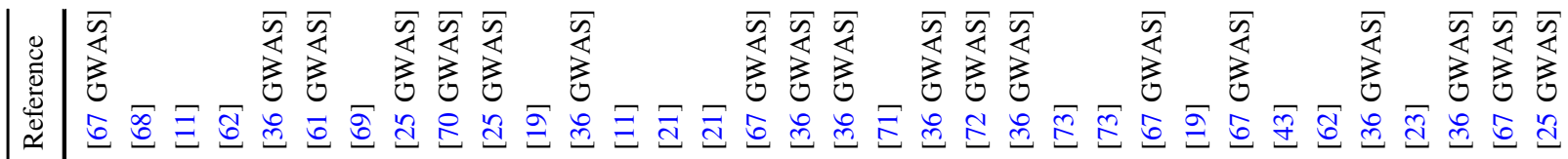

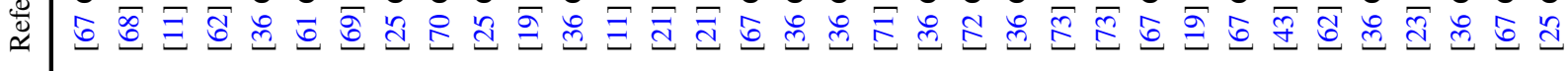

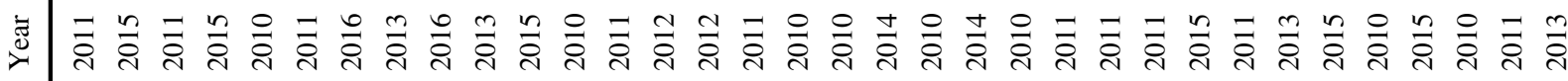

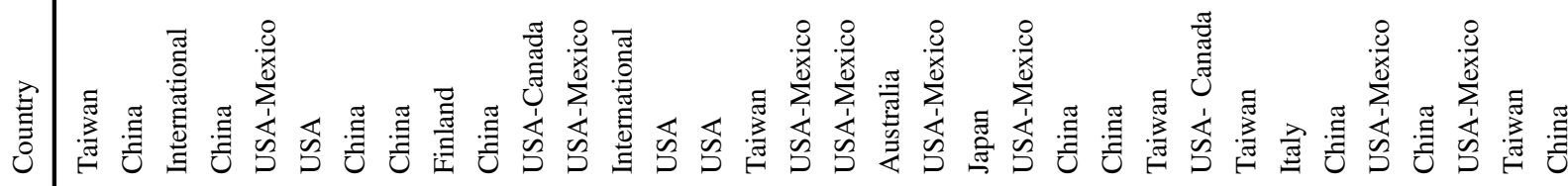

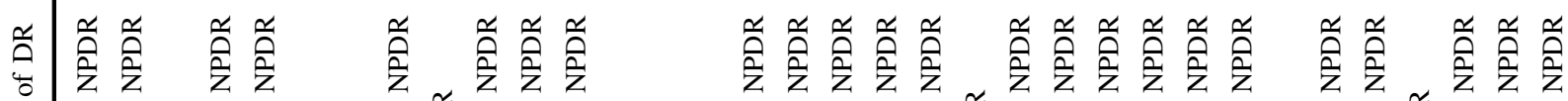

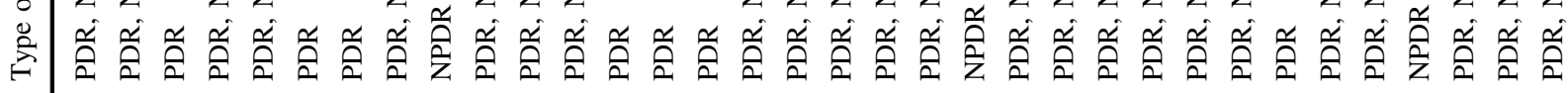

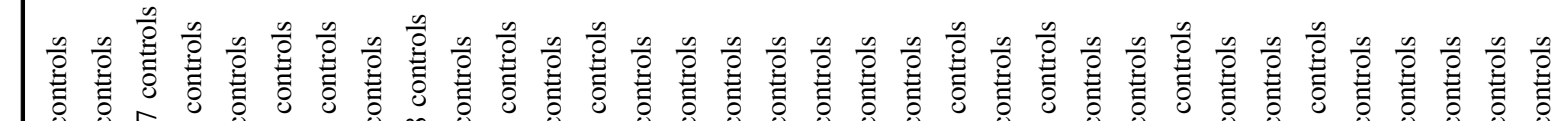

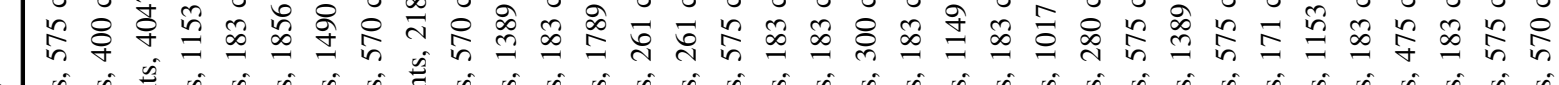

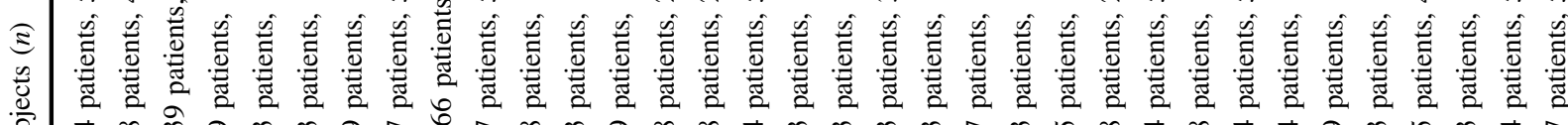

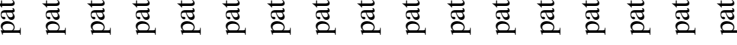

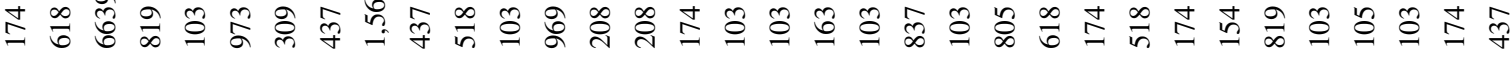 \\ ลิ

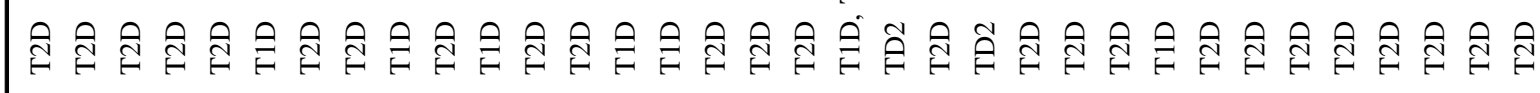

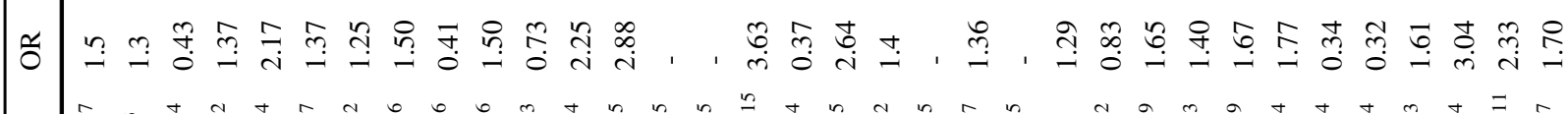

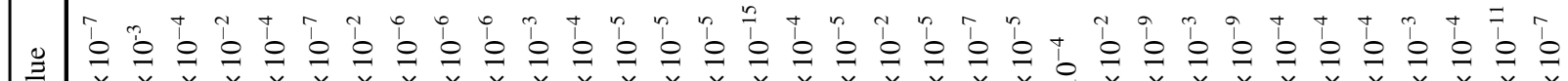

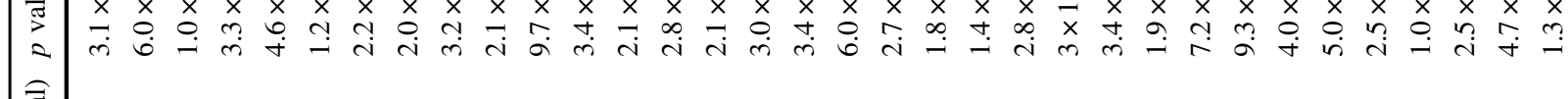

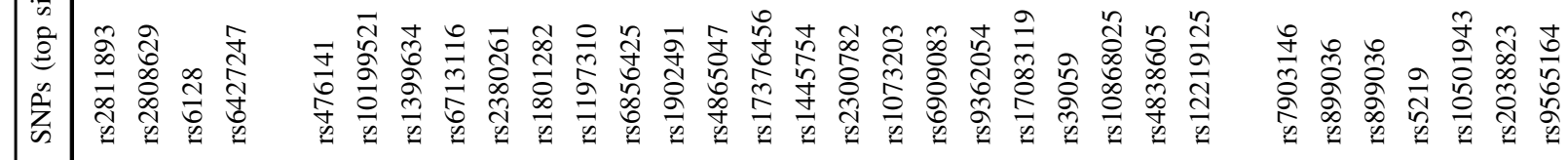

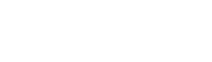

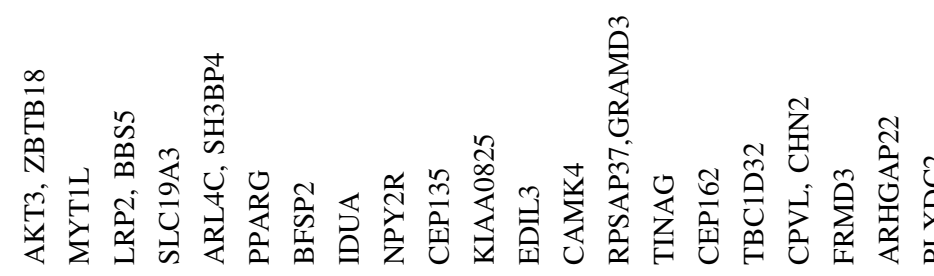

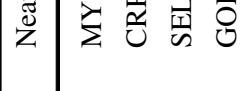

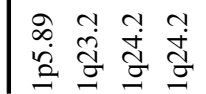

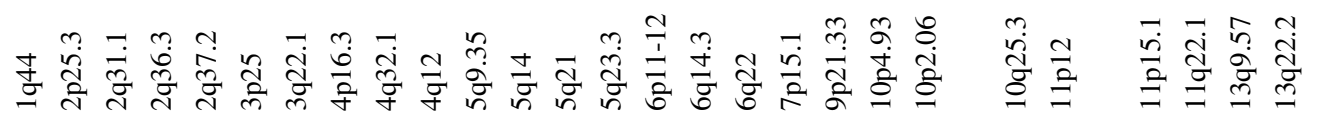
章 


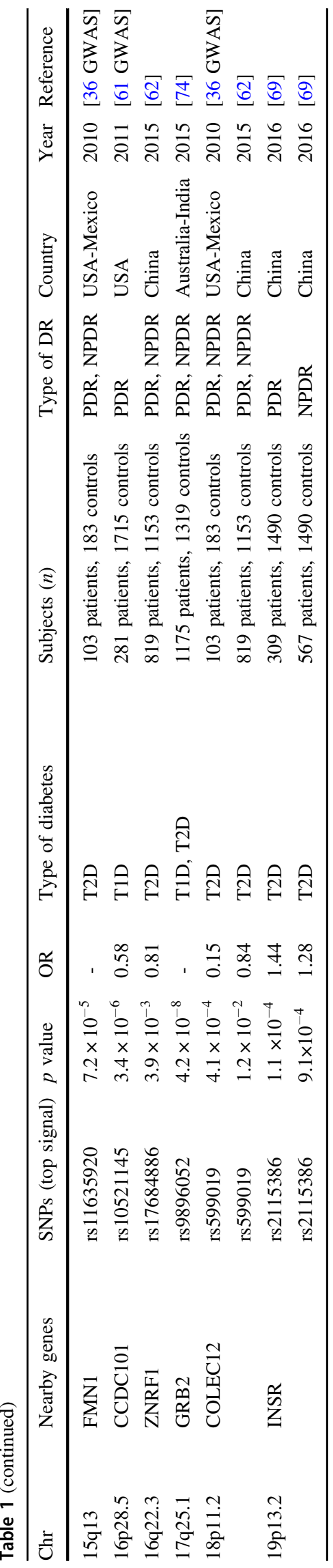

these genes to biological processes and pathways. Our analyses revealed that majority of these genes belong to various biological pathways known to have a significant contribution to the DR pathology including insulin signaling, angiogenesis (HIF-1 signaling, regulation of blood vessel size, VEGF signaling), inflammation (IL-6 signaling, leukocyte adhesion, TGF- $\beta$ and TNF signaling), lipid metabolic process, neurogenesis (neural cells differentiation, neurotrophin signaling), protein kinase signaling (Jak-STAT, PI3K-Akt, MAPK, Ras and mTOR signaling) and regulation of endothelial cell / leukocytes interaction (cell adhesion molecules, cell migration) (Table 2).

\section{Insulin signaling}

A total of 9 genes (AKT3, GRB2, SLC2A1, KCNJ11, TBC1D4, CEP135, UCHL3, INSR, and HNMT) were mapped to insulin signaling pathway. Insulin activates the insulin receptor (INSR) tyrosine kinase which phosphorylates numerous signaling partners. In the retina, disrupted INSR signaling has been shown to produce cellular dysfunction [20]. Among the INSR phosphorylated signaling partners, the activation of the AKT3/PKB and the $\mathrm{PKC} \zeta$ cascade regulates diverse biochemical responses including glycogen synthesis, protein synthesis, and autophagy. One such biochemical response is mediated by GRB2 activation, which forms a stable complex with phosphorylated insulin receptor substrate (IRS-1) and the SH2 domain-containing oncogenic protein, SHC. CEP135 (Centrosomal protein $135 \mathrm{kDa}$ ), expressed in the retina, encodes a centrosomal protein required for centriolecentriole cohesion during the interphase of the cell cycle [21]. CEP135 interacts with SMAD9, a critical component in the TGF- $\beta$ signaling pathway which is also upregulated in diabetes and diabetic retinopathy [21]. KCNJ11 (Potassium voltage-gated channel subfamily $\mathrm{J}$ member 11) encodes for a potassium channel controlled by G-proteins and was found to be associated with the sulfonylurea receptor. The common variant of KCNJ11 (rs5219) has a strong association with DR [22, 23]. SLC2A1 (Solute carrier family 2, member 1 also known as GLUT1) is expressed in endothelial and epithelial barriers including the retinal capillary endothelium, retinal pigment epithelium, and the basal cells of the corneal epithelium in the eye [24]. SLC2A1 is an important target for $\mathrm{DR}$ as it is the only glucose transporter between the blood and retina [24]. The knockdown by intraocular injections of a pool of siRNAs directed against SLC2Al mRNA significantly reduced retinal glucose levels in diabetic mice. TBC1D4 (TBC1 domain family, member 4) is known to play a role in insulin signaling in the retina and DR pathogenesis [25]. UCHL3 (Ubiquitin carboxyl- 
Table 2 Candidate genes and important signaling pathways associated with diabetic retinopathy

\begin{tabular}{|c|c|}
\hline Signaling pathways & Candidate genes \\
\hline Insulin signaling & $\begin{array}{l}\text { AKT3,GRB2,SLC2A1,KCNJ11, } \\
\text { TBC1D4,CEP135,UCHL3, HNMT, } \\
\text { INSR }\end{array}$ \\
\hline Angiogenesis & EDIL3,NOS3,SERPINE1,PLXDC2 \\
\hline Blood vessel development & $\begin{array}{l}\text { ACE,AGT,EDN1,NOS3,SELP, } \\
\text { TCF7L2 }\end{array}$ \\
\hline HIF-1 signaling & $\begin{array}{l}\text { AKT3,EDN1, SLC2A1,NOS3, } \\
\text { SERPINE1,VEGFA }\end{array}$ \\
\hline Patterning of blood vessels & EDN1,VEGFA, GRAMD3 \\
\hline $\begin{array}{l}\text { Regulation of blood vessel } \\
\text { size }\end{array}$ & ADRB3,AGT,AGTR1,EDN1,NOS3 \\
\hline Response to hypoxia & ACE,EDN1, MTHFR,NOS3,TGFB1 \\
\hline VEGF signaling & AKT3,GRB2,NOS3,VEGFA \\
\hline \multicolumn{2}{|l|}{ Inflammation: } \\
\hline IL-6 signaling & AKT3,GRB2,ICAM1, CRP \\
\hline Leukocyte adhesion & ICAM1,ITGB1,SELP,TNF, \\
\hline NF-kappa B activation & AGT,ICAM1,PARP1,TGFB1,TNF \\
\hline NF-kappa B inhibition & COMMD6 \\
\hline TGF-beta signaling & $T G F B 1, T N F$ \\
\hline TNF signaling & AKT3,EDN1,ICAM1,PARP1,TNF \\
\hline Lipid metabolic process & LRP2,PON1,ARLAC,COLEC12 \\
\hline \multicolumn{2}{|l|}{ Neurogenesis: } \\
\hline Apoptotic process & $A P I 5, G O R A B$ \\
\hline Neural cells differentiation & ZBTB18,ZNRF1 \\
\hline $\begin{array}{l}\text { Neuroactive ligand-receptor } \\
\text { interaction }\end{array}$ & $A D R B 3, A G T R, N P Y, N P Y 2 R$ \\
\hline Neurotrophin signaling & AKT3,CAMK4,GRB2 \\
\hline Jak-STAT signaling & $A K T 3, G R B 2$ \\
\hline PI3K-Akt signaling & $\begin{array}{l}\text { AKT3,COL4A4, GRB2,ITGB1,NOS3, } \\
\text { VEGFA }\end{array}$ \\
\hline Protein kinase cascade & $A D R B 3, A G T, E D N 1, T G F B 1, T N F$ \\
\hline MAPK signaling & AKT3,GRB2,TGFB1,TNF \\
\hline Ras signaling & AKT3,GRB2,VEGFA \\
\hline mTOR signaling & $A K T 3, T N F, V E G F A$ \\
\hline \multicolumn{2}{|c|}{ Regulation of endothelial cell / leukocytes interaction } \\
\hline $\begin{array}{l}\text { Cell adhesion molecules } \\
\text { (CAMs) }\end{array}$ & $\begin{array}{l}\text { FMN1,ICAM1,ITGB1, SELP, } \\
\text { COL4A4,ITGB1 }\end{array}$ \\
\hline ECM-receptor interaction & $A C E, A G T, N O S 3, T G F B 1$ \\
\hline $\begin{array}{l}\text { Regulation of endothelial } \\
\text { cell migration }\end{array}$ & $A G T, E D N 1, T G F B 1$ \\
\hline $\begin{array}{l}\text { Regulation of cellular } \\
\text { localization }\end{array}$ & $\begin{array}{l}A G T, E D N 1, K C N J 11, T C F 7 L 2, \\
T G F B 1, T N F\end{array}$ \\
\hline Regulation of cell migration & $\begin{array}{l}\text { ACE,AGT,EDN1,ICAM1,ITGB1, } \\
\text { NOS3,SELP,TGFB1 }\end{array}$ \\
\hline
\end{tabular}

terminal esterase L3) is a deubiquitinating enzyme playing a role in the maintenance of ubiquitin levels within the cell through processing of ubiquitin precursors and ubiquitinated proteins. Several studies have shown the role of
UCHL3 in insulin signaling and retinal maintenance in stress conditions [26, 27].

\section{Angiogenesis}

The crucial role of angiogenesis in DR has been recognized since 1985 when Rand et al. reported how changes in retinal venular caliber could predict vision loss [28]. VEGF is a heparin-binding homodimeric glycoprotein that acts via endothelial-specific receptor tyrosine kinases, among which VEGFR2 is the main VEGF receptor regulating angiogenesis. VEGF is one of the targets of the HIF (HypoxiaInducible Factor), a basic helix-loop-helix transcription factor that regulates the response to hypoxia. HIF induces expression of proteins controlling glucose metabolism, cell proliferation, vascularization, and blood vessel development such as SELP (P-selectin), EDN1 (Endothelin 1), LDHA (Lactate dehydrogenase-A), TGF $\beta 1$, and b-FGF (basic fibroblast growth factor) [29]. VEGF was amongst the first factors known to regulate retinal neovascularization and blood-retinal barrier (BRB) breakdown in DR [30]. The absence of the SLC2A1 carrier in neovascular tissue of PDR is a sign of the loss of glucose selective permeability [31] and GRB2 participates in the MAPK pathway via Ras in response to vascular endothelial growth factor signaling [32].

ACE, AGT and AGTR belong to the renin-angiotensin system, a crucial pathway which regulates blood pressure. The production of Ang II within the retina leads to a series of hemodynamic and growth promoting effects that trigger DR development [33]. Ang-II induces capillary growth, vascular permeability, and an increase in oxidative stress via stimulation of growth factors such as TGF- $\beta$, VEGF, and PDGF [34]. Furthermore, the increase of Ang-II has been shown in diabetic patients, particularly with microangiopathy and microvascular damage [35]. EDIL3 (EGF-like repeats and discoidin domains 3 ) encodes for an integrin ligand which plays an important role in mediating angiogenesis and vessel wall remodeling. It also influences retinal endothelial cell behavior [36]. The EDN1 (Endothelin 1) gene encodes a protein that is primarily produced in vascular endothelium, vascular smooth muscle cells, macrophages, leukocytes, cardiomyocytes, and fibroblasts [37]. Endothelin 1 plays a pivotal role in endothelial dysfunction, one of the significant elements in the pathogenesis of DR [38]. Studies have shown high EDN1 expression in vascular and extravascular sites in the retina and its contribution to abnormal retinal hemodynamics in DR [39].

Endothelial nitric oxide synthase (eNOS) plays an essential role in maintaining vascular homeostasis. Deficiency in eNOS expression coupled with concomitant activation of inducible nitric oxide synthase (iNOS) triggers 
highly reactive nitrogen species (RNS) formation, thus, leading to oxidative stress and accelerated retinopathy [40]. PLXDC2 (Plexin domain-containing protein 2), also known as TEM7R (tumor endothelial marker seven-related protein), has been implicated in neurogenesis and angiogenesis $[19,41]$. PDR results in part from the formation of fibrovascular membranes (FVMs) in the posterior fundus. Tumor endothelial marker 7 (TEM7) is a protein that is highly expressed in the endothelial cells of tumors. TEM7 has been shown to play a significant role in the proliferation and maintenance of neovascular endothelial cells in the FVMs [42]. TCF7L2 (Transcription factor 7-like 2) participates in the WNT signaling pathway and regulates MYC expression by binding to its promoter in a sequence-specific manner [43]. ARHGAP22 encodes a Rho family GTPase protein, which is a component in the regulation of endothelial cell capillary tube development during angiogenesis [44]. Similar to PLXDC2, ARHGAP22 has been implicated in PDR and is involved in endothelial cell angiogenesis.

\section{Inflammation}

Eleven genes associated with DR (CRP, AKT3, GRB2, ICAM1, ITGB1, SELP, TNF, AGT, PARP1, COMMD6, and $E D N 1)$ were mapped to pathways involved in inflammation. Several studies have shown that patients exhibit higher blood levels of inflammatory markers such as C-reactive protein (CRP), interleukin-6 (IL-6), transforming growth factor (TGF- $\beta$ ), tumor necrosis factor-alpha (TNF- $\alpha$ ) [27], cyclooxygenase-2 (COX-2), and interleukin-1 (IL-1) $[45,46]$. Moreover, soluble TNF-receptor levels have been associated with an increased risk of severe DR [25]. IL-6 is a cytokine that provokes a broad range of cellular and physiological responses including the immune response, inflammation, hematopoiesis, and oncogenesis by regulating cell growth, gene activation, proliferation, survival, and differentiation. AKT3, CRP, ICAM1 and GRB2 are known to be involved in the IL-6 signaling. AKT3, a member of the AKT (or PKB) serine/threonine-protein kinase family, regulates many processes including metabolism, proliferation, cell survival, growth and angiogenesis. In particular, AKT3 has been shown to be stimulated by platelet-derived growth factor (PDGF), insulin, and insulin-like growth factor 1 (IGF1), both implicated in proliferative retinopathy $[21,47]$. The GRB2 gene codes for an adapter protein that is involved in the Ras-mediated pathway which leads to the activation of transcription factors such as EIKI and NF-IL-6 (C/EBP-Beta). Burton et al. [32]. recently described GRB2 as a promising candidate for DR susceptibility because increase of this protein in mouse retina was correlated to retinal stress leading to DR. Also, GRB2 protein is expressed in all layers of the human retina. The COMMD6
(COMM domain containing 6) gene belongs to a family of NF-kB inhibiting proteins characterized by the presence of a COMM domain and down-regulates TNF-induced NF-kB activation [48]. PARP1 (poly(ADP-ribose) polymerase), a DNA repair enzyme activated by oxidative damage, mediates the hyperglycemia-induced activation of NF-kB, pro-inflammatory molecules, cytokines, and iNOS. Its overexpression leading to a depletion of ATP, NAD + and NADH [49]. The loss of these cofactors cause an impairment in glycolysis and mitochondrial respiration that affect cellular viability. The TNF gene encodes for a proinflammatory cytokine which is member of the tumor necrosis factor superfamily. Studies have described the involvement of TNF- $\alpha$ in diabetic retinal microvascular damage and drugs that target TNF- $\alpha$ have been shown to reduce leukostasis, retinal vascular leakage, and retinal cell death in animal models [50] . TGF- $\beta$, a cytokine implicated in multiple cellular functions including proliferation, differentiation, adhesion, and migration, has been shown to be involved in the basement membrane thickening and matrix accumulation in the blood vessels [51]. The gene expression profile of retinal vessels isolated from streptozotocin- treated rats revealed an increased expression in 20 genes of the TGF- $\beta$ signaling pathways [52]. ICAM1, ITGB1 and SELP are particularly important in leukocyte adhesion, one of the earliest signs of retinal complications. ICAM1 (Intercellular adhesion molecule 1 or CD18) is a member of the ICAM proteins that act as ligands for the leukocyte adhesion protein, LFA-1. This gene encodes for a cell surface glycoprotein, typically on endothelial cells, whose expression is induced by increased levels of VEGF. Specific inhibition of ICAM1 in diabetic animals leads to reduction of leukostasis and BRB breakdown [53]. The ITGB1 (Integrin, beta 1 ) belongs to the integrins family and plays a pivotal role in PDR and proliferative vitreo-retinopathy due to its contribution to the terminal event of tractional retinal detachment [54].

\section{Neurogenesis}

Several DR associated genes (API5, GORAB, ZBTB18, ZNRF1, ADRB3, AGTR, NPY, NPY2R, AKT3, CAMK4, and $G R B 2$ ) belong to the neurological processes. Despite the retina's peripheral localization, it is actually part of the central nervous system. DR is a multifactorial disease involving not only the vasculature, but also the neurons and glia and studies have suggested that neuronal changes in the retina may occur before vascular alterations $[55,56]$. There is sufficient evidence of neurodegenerative changes in DR including increased apoptosis of ganglion cells, glial cell reactivity, microglial activation, and altered glutamate metabolism [57]. 
Neurotrophins (NTs) are a family of growth factors that mediate the growth, differentiation, and survival of developing neurons. A significant increase was observed in the expression of NT-3 and NT-4 in vitreous samples from PDR patients compared to non-diabetic controls [58]. Interestingly, AKT3 and GRB2 have been shown to participate in NT signaling. API5 (Apoptosis inhibitor 5) is an anti-apoptotic factor which acts as a suppressor of the transcription factor E2F1 which induces apoptosis and also interacts with, and negatively regulates, Acinus, a nuclear factor involved in apoptotic DNA fragmentation. CAMK4 (Calcium/calmodulin-dependent protein kinase IV) acts in the calcium-triggered CaMKKCaMK4 signaling cascade. This kinase is expressed in the brain, spleen, thymus, and regulates the activity of several transcription factors implicated in the immune response, inflammation, and memory consolidation [59]. Neuropeptide Y (NPY) and its receptor (NPY2R) play a pivotal role in the central nervous system regulating many physiological processes. The Leu7Pro (codon 7) polymorphism in NPY was identified as a risk factor for DR development in a wellcharacterized cohort of patients with Type 2 diabetes [16]. ZBTB18 (Zinc finger and BTB domain containing 18) encodes a $\mathrm{C} 2 \mathrm{H} 2$-type zinc finger protein which acts as a transcriptional repressor of key pro-neurogenic genes such as Neurogenin2 and NeuroD1[60]. ZBTB18 is also involved in various developmental processes such as myogenesis and other aspects of brain development [61]. ZNRF1 (Zinc and ring finger 1, E3 ubiquitin protein ligase) is an E3 ubiquitin-protein ligase that mediates the ubiquitination of AKT1 and glutamate-ammonia ligase (GLUL), playing a role in neuronal cell differentiation. ZNRF1 regulates neurodegeneration, maintenance of neuronal transmission, plasticity, and Schwann cell differentiation in DR [62].

\section{Regulation of endothelial cell / leukocytes interaction}

An important cause of damage in the vascular endothelium in DR is leukocyte activation and migration that is mediated by the specific adhesion molecules expressed on the cell surface of leukocytes and the endothelium. A significant correlation between the number of leukocytes accumulated within the vessel and capillary damage in the retina has been identified in post-mortem DR patients [63]. Moreover, pre-clinical animal studies of early DR have also highlighted the disruption of the retinal endothelium caused by adhering leukocytes and the subsequent increase of the vascular permeability [64]. Thirteen genes (ACE, AGT, COLAA4, EDN1, FMN1, ICAM1, ITGB1, KCNJ11, NOS3, SELP, TCF7L2, TGFB1, TNF) were mapped to this pathway. ICAM1, EDN1, and SELP are important markers of endothelial dysfunction that have been linked with the development of DR [65]. ICAM-1 level increases in the diabetic retina, even in the early stages of DR. Endothelial complications in DR are dramatically reduced in animals treated with anti-ICAM-1 antibodies [64]. EDN-1 is known to be a potent vasoconstrictor molecule, implicated in the disruption of retinal hemodynamics and DR progression [39]. COLAA4 (Collagen, type IV, alpha 4) encodes one of the six subunits of type IV collagen, the major structural component of basement membranes and modification of collagen metabolism in the basement membrane is associated with DR [66]. FMN1 (Formin 1) is involved in cell adhesion and morphogenesis [36].

\section{Conclusions}

In this review, we compiled a comprehensive list of genetic factors associated with DR. Further analyses revealed the biological functions of these genes in DR pathogenesis. The identification of genetic factors and their contribution to DR etiology will allow for tailored pharmacogenomics approaches for the treatment of DR.

\section{Summary}

- Diabetic retinopathy (DR) is a microvascular disease of the retina and the leading cause of visual disability in diabetic patients.

- Genetic factors have shown to play a pivotal role in DR onset, and several candidate genes have been associated with its progression.

- This review presents an insight into genes associated with DR and their role in various biological functions and signaling pathways.

Acknowledgements This research was supported by an NIH/NEI grant to Shruti Sharma at the Augusta University (5R01-EY026936).

\section{Compliance with ethical standards}

Conflict of interest The authors declare that they have no conflict of interest.

Publisher's note: Springer Nature remains neutral with regard to jurisdictional claims in published maps and institutional affiliations.

\section{References}

1. Stitt Alan W, Lois N, Medina Reinhold J, Adamson P, Curtis Timothy M. Advances in our understanding of diabetic retinopathy. Clin Sci. 2013;125:1-17.

2. Aiello LM. Perspectives on diabetic retinopathy. Am J Ophthalmol. 2003;136:122-35. 
3. Hietala K, Forsblom C, Summanen P, Groop P-H.on behalf of the FinnDiane Study Group. Heritability of proliferative diabetic retinopathy. Diabetes. 2008;57:2176-80.

4. Stitt AW, Curtis TM, Chen M, Medina RJ, McKay GJ, Jenkins A, et al. The progress in understanding and treatment of diabetic retinopathy. Prog Retin Eye Res. 2016;51:156-86.

5. Osaadon P, Fagan XJ, Lifshitz T, Levy J. A review of antiVEGF agents for proliferative diabetic retinopathy. Eye. 2014;28:510-20.

6. Cheung N, Wong IY, Wong TY. Ocular Anti-VEGF therapy for diabetic retinopathy: overview of clinical efficacy and evolving applications. Diabetes Care. 2014;37:900-5.

7. Safi SZ, Qvist R, Kumar S, Batumalaie K, Ismail ISB. Molecular mechanisms of diabetic retinopathy, general preventive strategies, and novel therapeutic targets. Biomed Res Int. 2014;2014:801269.

8. Rask-Madsen C, King GL. Vascular complications of diabetes: mechanisms of injury and protective factors. Cell Metab. 2013;17:20-33.

9. Abhary S, Hewitt AW, Burdon KP, Craig JE. A systematic metaanalysis of genetic association studies for diabetic retinopathy. Diabetes. 2009;58:2137-47.

10. Liew G, Klein R, Wong TY. The role of genetics in susceptibility to diabetic retinopathy. Int Ophthalmol Clin. 2009;49:35-52.

11. Sobrin L, Green T, Sim X, Jensen RA, Tai ES, Tay WT, et al. Candidate gene association study for diabetic retinopathy in persons with type 2 diabetes: the candidate gene association resource (CARe). Invest Ophthalmol \& Vis Sci. 2011;52:7593-602.

12. $\mathrm{Ng}$ DPK. Human genetics of diabetic retinopathy: current perspectives. J Ophthalmol. 2010;2010:172593.

13. Falck AAK, Knip JM, Ilonen JS, Laatikainen LT. Genetic markers in early diabetic retinopathy of adolescents with type i diabetes. J Diabetes Complicat. 1997;11:203-7.

14. Hawrami K, Hitman GA, Rema M, Snehalatha C, Viswanathan M, Ramachandran A, et al. An association in non-insulindependent diabetes mellitus subjects between susceptibility to retinopathy and tumor necrosis factor polymorphism. Hum Immunol. 1996;46:49-54.

15. Sakane N, Yoshida T, Yoshioka K, Nakamura Y, Umekawa T, Kogure A, et al. 3-Adrenoreceptor gene polymorphism: a newly identified risk factor for proliferative retinopathy in NIDDM Patients. Diabetes. 1997;46:1633-6.

16. Niskanen L, Voutilainen-Kaunisto R, Teräsvirta M, Karvonen MK, Valve R, Pesonen U, et al. Leucine 7 to proline 7 polymorphism in the neuropeptide y gene is associated with retinopathy in Type 2 diabetes. Exp Clin Endocrinol Diabetes. 2000;108:235-6.

17. Kao YL, Donaghue K, Chan A, Knight J, Silink M. A variant of paraoxonase (PON1) gene is associated with diabetic retinopathy in IDDM. J Clin Endocrinol \& Metab. 1998;83:2589-92.

18. Alcolado JC, Baroni MG, Li SR, Galton DJ. Genetic variation around the collagen IV 1a gene locus and proliferative retinopathy in type 2 diabetes mellitus. Hum Hered. 1993;43:126-30.

19. Hosseini SM, Boright AP, Sun L, Canty AJ, Bull SB, Klein BEK, et al. The association of previously reported polymorphisms for microvascular complications in a meta-analysis of diabetic retinopathy. Hum Genet. 2015;134:247-57.

20. Reiter CEN, Gardner TW. Functions of insulin and insulin receptor signaling in retina: possible implications for diabetic retinopathy. Prog Retin Eye Res. 2003;22:545-62.

21. Grassi MA, Tikhomirov A, Ramalingam S, Lee KE, Hosseini SM, Klein BEK, et al. Replication analysis for severe diabetic retinopathy. Invest Ophthalmol \& Vis Sci. 2012;53:2377-81.

22. Koo BK, Cho YM, Park BL, Cheong HS, Shin HD, Jang HC, et al. Polymorphisms of KCNJ11 (Kir6.2 gene) are associated with Type 2 diabetes and hypertension in the Korean population. Diabet Med. 2007;24:178-86.

23. Liu N-J, Wu H-H, Li Y-L, Yang Z, Tao X-M, Du Y-P, et al. An analysis of the association between a polymorphism of KCNJ11 and diabetic retinopathy in a Chinese Han population. Eur J Med Res. 2015;20:3.

24. Lu L, Seidel CP, Iwase T, Stevens RK, Gong Y-Y, Wang X, et al. Suppression of GLUT1; a new strategy to prevent diabetic complications. J Cell Physiol. 2013;228:251-7.

25. Sheu WHH, Kuo JZ, Lee IT, Hung Y-J, Lee W-J, Tsai H-Y, et al. Genome-wide association study in a Chinese population with diabetic retinopathy. Hum Mol Genet. 2013;22:3165-73.

26. Suzuki M, Setsuie R, Wada K. Ubiquitin carboxyl-terminal hydrolase 13 promotes insulin signaling and adipogenesis. Endocrinology. 2009;150:5230-9.

27. Shoelson SE, Lee J, Goldfine AB. Inflammation and insulin resistance. J Clin Investig. 2006;116:1793-801.

28. Rand LI, Krolewski AS, Aiello LM, Warram JH, Baker RS, Maki T. Multiple factors in the prediction of risk of proliferative diabetic retinopathy. New Engl J Med. 1985;313:1433-8.

29. Ziello JE, Jovin IS, Huang Y. Hypoxia-inducible factor (hif)-1 regulatory pathway and its potential for therapeutic intervention in malignancy and ischemia. Yale J Biol Med. 2007;80:51-60.

30. Aiello LP, Avery RL, Arrigg PG, Keyt BA, Jampel HD, Shah ST, et al. Vascular endothelial growth factor in ocular fluid of patients with diabetic retinopathy and other retinal disorders. New Engl J Med. 1994;331:1480-7.

31. Kumagai AK, Glasgow BJ, Pardridge WM. GLUT1 glucose transporter expression in the diabetic and nondiabetic human eye. Invest Ophthalmol \& Vis Sci. 1994;35:2887-94.

32. Burdon K, Fogarty R, Shen W, Abhary S, Kaidonis G, Appukuttan B, et al. Genome-wide association study for sightthreatening diabetic retinopathy reveals association with genetic variation near the GRB2 gene. Diabetologia. 2015;58: 1-10.

33. Marin Garcia PJ, Marin-Castaño ME. Angiotensin II-related hypertension and eye diseases. World J Cardiol. 2014;6:968-84.

34. Funatsu H, Yamashita H. Pathogenesis of diabetic retinopathy and the renin-angiotensin system. Ophthalmic Physiol Opt. 2003;23:495-501.

35. Toop MJ, Dallinger KJC, Jennings PE, Barnett AH. AngiotensinConverting Enzyme (ACE): relationship to insulin-dependent diabetes and microangiopathy. Diabet Med. 1986;3:455-7.

36. Fu Y-P, Hallman DM, Gonzalez VH, Klein BEK, Klein R, Hayes $\mathrm{MG}$, et al. Identification of diabetic retinopathy genes through a genome-wide association study among Mexican-Americans from Starr County, Texas. J Ophthalmol. 2010;2010:861291.

37. Freeman BD, Machado FS, Tanowitz HB, Desruisseaux MS. Endothelin-1 and its role in the pathogenesis of infectious diseases. Life Sci. 2014;118:110-9.

38. Rask-Madsen C, King GL. Mechanisms of Disease: endothelial dysfunction in insulin resistance and diabetes. Nat Clin Pract End Met. 2007;3:46-56.

39. Kalani M. The importance of endothelin-1 for microvascular dysfunction in diabetes. Vasc Health Risk Manag. 2008;4:1061-8.

40. Montufar-Solis D, Garza T, Vigneswaran N, Klein JR. Soluble gp130 promotes intestinal epithelial hyperplasia during reovirus infection. Int J Exp Pathol. 2010;91:276-80.

41. Miller-Delaney SFC, Lieberam I, Murphy P, Mitchell KJ. Plxdc2 is a mitogen for neural progenitors. PLoS ONE. 2011;6:e14565.

42. Yamaji Y, Yoshida S, Ishikawa K, Sengoku A, Sato K, Yoshida A, et al. TEM7 (PLXDC1) in neovascular endothelial cells of fibrovascular membranes from patients with proliferative diabetic retinopathy. Invest Ophthalmol \& Vis Sci. 2008;49:3151-7.

43. Ciccacci C, Di Fusco D, Cacciotti L, Morganti R, D’Amato C, Novelli $\mathrm{G}$, et al. TCF7L2 gene polymorphisms and type 2 
diabetes: association with diabetic retinopathy and cardiovascular autonomic neuropathy. Acta Diabetol. 2013;50:789-99.

44. Katoh M, Katoh M. Identification and characterization of ARHGAP24 and ARHGAP25 genes in silico. Int $\mathrm{J}$ Mol Med. 2004;14:333-8.

45. Joussen AM, Poulaki V, Le ML, Koizumi K, Esser C, Janicki H, et al. A central role for inflammation in the pathogenesis of diabetic retinopathy. FASEB J. 2004;18:1450-2.

46. Kern TS. Contributions of inflammatory processes to the development of the early stages of diabetic retinopathy. Exp Diabetes Res. 2007;2007:95103.

47. Sandirasegarane L, Kester M. Enhanced stimulation of Akt-3/ protein kinase $b-\gamma$ in human aortic smooth muscle cells. Biochem Biophys Res Commun. 2001;283:158-63.

48. de Bie P, van de Sluis B, Burstein E, Duran Karen J, Berger R, Duckett Colin S, et al. Characterization of COMMD proteinprotein interactions in NF- $\mathrm{KB}$ signalling. Biochem J. 2006;398(Pt 1):63-71.

49. Garcia Soriano F, Virag L, Jagtap P, Szabo E, Mabley JG, Liaudet L, et al. Diabetic endothelial dysfunction: the role of poly(ADPribose) polymerase activation. Nat Med. 2001;7:108-13.

50. Joussen AM, Doehmen S, Le ML, Koizumi K, Radetzky S, Krohne TU, et al. TNF- $\alpha$ mediated apoptosis plays an important role in the development of early diabetic retinopathy and longterm histopathological alterations. Mol Vis. 2009;15:1418-28.

51. LEASK A, ABRAHAM DJ. TGF- $\beta$ signaling and the fibrotic response. FASEB J. 2004;18:816-27.

52. Gerhardinger C, Dagher Z, Sebastiani P, Park YS, Lorenzi M. The transforming growth factor- $\beta$ pathway is a common target of drugs that prevent experimental diabetic retinopathy. Diabetes. 2009;58:1659-67.

53. Joussen AM, Murata T, Tsujikawa A, Kirchhof B, Bursell S-E, Adamis AP. Leukocyte-mediated endothelial cell injury and death in the diabetic retina. Am J Pathol. 2001;158:147-52.

54. Kupper TS, Ferguson TA. A potential pathophysiologic role for alpha 2 beta 1 integrin in human eye diseases involving vitreoretinal traction. FASEB J. 1993;7:1401-6.

55. Kadłubowska J, Malaguarnera L, Wąż P, Zorena K. Neurodegeneration and neuroinflammation in diabetic retinopathy: potential approaches to delay neuronal loss. Curr Neuropharmacol. 2016;14:831-9.

56. Bloodworth JM Jr. Diabetic retinopathy. Diabetes. 1962;11:1-22.

57. Whitmire W, Al-Gayyar MMH, Abdelsaid M, Yousufzai BK, ElRemessy AB. Alteration of growth factors and neuronal death in diabetic retinopathy: what we have learned so far. Mol Vis. 2011;17:300-8.

58. Abu El-Asrar AM, Mohammad G, De Hertogh G, Nawaz MI, Van Den Eynde K, Siddiquei MM, et al. Neurotrophins and neurotrophin receptors in proliferative diabetic retinopathy. PLoS ONE. 2013;8:e65472.

59. Ban N, Yamada Y, Someya Y, Ihara Y, Adachi T, Kubota A, et al. Activating transcription factor-2 is a positive regulator in CaM kinase IV-induced human insulin gene expression. Diabetes. 2000;49:1142-8.
60. Xiang C, Baubet V, Pal S, Holderbaum L, Tatard V, Jiang P, et al. RP58/ZNF238 directly modulates proneurogenic gene levels and is required for neuronal differentiation and brain expansion. Cell Death Differ. 2011;19:692.

61. Grassi MA, Tikhomirov A, Ramalingam S, Below JE, Cox NJ, Nicolae DL. Genome-wide meta-analysis for severe diabetic retinopathy. Hum Mol Genet. 2011;20:2472-81.

62. Peng D, Wang J, Zhang R, Jiang F, Tang S, Chen M, et al. Common variants in or near ZNRF1, COLEC12, SCYL1BP1 and API5 are associated with diabetic retinopathy in Chinese patients with type 2 diabetes. Diabetologia. 2015;58:1231-8.

63. McLeod DS, Lefer DJ, Merges C, Lutty GA. Enhanced expression of intracellular adhesion molecule-1 and P-selectin in the diabetic human retina and choroid. Am J Pathol. 1995;147:642-53.

64. Miyamoto K, Khosrof S, Bursell S-E, Rohan R, Murata T, Clermont $\mathrm{AC}$, et al. Prevention of leukostasis and vascular leakage in streptozotocin-induced diabetic retinopathy via intercellular adhesion molecule-1 inhibition. Proc Natl Acad Sci. 1999;96:10836-41.

65. van den Oever IAM, Raterman HG, Nurmohamed MT, Simsek S. Endothelial dysfunction, inflammation, and apoptosis in diabetes mellitus. Mediat Inflamm. 2010;2010:15.

66. Roux E, Cherbit G, Regnault F. Collagen-induced platelet aggregation and collagen glycosyl-transferase activity in diabetic patients. Thromb Res. 1977;11:847-58.

67. Huang Y-C, Lin J-M, Lin H-J, Chen C-C, Chen S-Y, Tsai C-H, et al. Genome-wide association study of diabetic retinopathy in a Taiwanese population. Ophthalmology. 2011;118:642-8.

68. Peng D, Wang J, Zhang R, Tang S, Jiang F, Chen M, et al. Creactive protein genetic variant is associated with diabetic retinopathy in Chinese patients with type 2 diabetes. BMC Endocr Disord. 2015;15:8.

69. Cheung CY, Hui EY, Lee CH, Kwok KH, Gangwani RA, Li KK, et al. Impact of genetic loci identified in genome-wide association studies on diabetic retinopathy in chinese patients with type 2 diabetes. Invest Ophthalmol Vis Sci. 2016;57:5518-24.

70. Porta M, Toppila I, Sandholm N, Hosseini SM, Forsblom C, Hietala $\mathrm{K}$, et al. Variation in SLC19A3 and protection from microvascular damage in type 1 diabetes. Diabetes. 2016;65:1022-30.

71. McAuley AK, Wang JJ, Dirani M, Connell PP, Lamoureux E, Hewitt AW. Replication of genetic loci implicated in diabetic retinopathygenetic loci implicated in diabetic retinopathy. Invest Ophthalmol Vis Sci. 2014;55:1666-71.

72. Awata T, Yamashita H, Kurihara S, Morita-Ohkubo T, Miyashita $\mathrm{Y}$, Katayama S, et al. A genome-wide association study for diabetic retinopathy in a japanese population: potential association with a long intergenic non-coding RNA. PLoS ONE. 2014;9: e111715.

73. Hu C, Zhang R, Yu W, Wang J, Wang C, Pang C, et al. CPVL/ CHN2 genetic variant is associated with diabetic retinopathy in Chinese type 2 diabetic patients. Diabetes. 2011;60:3085-9.

74. Burdon KP, Fogarty RD, Shen W, Abhary S, Kaidonis G, Appukuttan B, et al. Genome-wide association study for sight-threatening diabetic retinopathy reveals association with genetic variation near the GRB2 gene. Diabetologia. 2015;58:2288-97. 